\title{
Assessment of the styloid process by cone beam computed tomography
}

\begin{abstract}
Objective: the aim of the study was to assess the length, angulations and the pattern of ossification of the Styloid process (SP) and to know if any correlation exists between them.
\end{abstract}

Method: 50 patients of CBCT, TMJ views were considered, a total of $87 \mathrm{tmjs}$ were viewed using ORTHOPHOS XG3D X-ray system. The length, mediolateral (MLA), anteroposterior angulation (APA) was measured. The morphology was identified on 3D images. Person's Correlation coefficient was used for statistical analysis.

Result: of the 87 scan. The Mean length of SP in males was $32.10 \mathrm{~mm}$ and in females was $31.62 \mathrm{~mm}$. There was no statistical significance between sides and between the length and age. The mean MLA in males was $80.6^{\circ}$ and in females it was $82.4^{\circ}$. MLA on right was $81.4^{\circ}$ and left was $81.3^{\circ}$ the mean APA in males and females was 25.2 and 31.1 respectively, In this study we found no correlation between length, age and agulation of the styloid process.

Conclusion: This study indicates that with an increase in length there is no significant increase in angulations. Age and gender showed no correlation with length. During evaluation of the Stylohyoid complex (SHC) length, angulations and morphology should be considered

Keywords: styloid process, orofacial pain, eagles syndrome, CBCT
Volume 2 Issue 5 - 2017

\author{
Thanuja Ramadoss, Karan Sha
}

Department of Oral Medicine, India

Correspondence: Thanuja Ramadoss, Department of Oral Medicine, Diagnosis and Radiology, MGVSKBH Dental College, Panchavati, Nashik- 422003, Tel +910805540684, Email i2ramesh@gmail.com

Received: March 22, 2017| Published: April 05, 2017
Abbreviations: SP, styloid process; MLA, mediolateral; APA, anteroposterior angulation; SHC, stylohyoid complex; CBCT, cone beam computed tomography; APA, antero posterior angle

\section{Introduction}

The Styloid process is a long slender and pointed bony process projecting downwards, forwards, and slightly medially from the temporal bone. It develops from Reichert's cartilage of $2^{\text {nd }}$ branchial arch. The ossification of the Styloid process (SP) starts at the end of pregnancy and undergoes calcification up to the first 8years of life. The postnatalstyloid chain consists of the styloid process of the temporal bone, the stylohyoid ligament, and the lesser horn of the hyoid bone. Ossification of the styloid chain may consist of a number of individual segments, separated by pseudoartroses. ${ }^{1}$

Elongated styloid process gives an array of symptoms as described by Eagle in 1937, hence the condition is also known as Eagle's syndrome; symptoms are secondary to calcification of the stylohyoid ligamentor to an elongated SP. ${ }^{2}$ The Normal length of the styloid process as stated by Eagle was $2.5 \mathrm{~cm} .{ }^{3}$ However there are authors who take up to $3 \mathrm{~cm}$ as normal value for the length of SP. Studies involving the Indian population has shown a wide range in length between 19$54 \mathrm{~mm} .{ }^{4}$ Most of them cases of elongated styloid are asymptomatic, when symptomatic may present as dull, aching pain localized in the throat, otalgia, hemifacial pain, dysphasia or an abnormal sensation of a foreign body in the pharynx., ${ }^{2,5}$

The SP is in close proximity to vital structures like then internal jugular vein, External carotid artery etc. An accentuated lateral deviation may cause the tip of the styloid process to press the external carotid artery. A posterior deviation of the elongated styloid process can irritate the last four cranial nerves, internal carotid artery and internal jugular vein. And a medial deviation may invade the tonsil causing painful symptoms. Anterior angulation can result in mucosal irritation and pressure on vital structures in the tonsils. ${ }^{6}$

Cone beam computed tomography (CBCT) is a technique that produces $3 \mathrm{D}$ digital imaging at reduced cost and less radiation for the patient than conventional CT scans and more beneficial than 2D imaging as there is no overlap of structures, so studying structures becomes more effective and reliable. ${ }^{7}$ The length and the orientation of the styloid process may be important in cases of orofacial pain and dysphagia though all cases of elongation do not present with symptoms, but when present may be due to the angulation of the Stylohyoid complex (SHC). So this study was conducted to assess the Angulation, length and pattern of calcification of the styloid process and to know if any correlation existed between them.

\section{Material and methods}

This retrospective study was undertaken in the department of Oral Medicine and Radiology, MGV'S KBH dental college, Nashik. The study consists of 50 patients whose CBC Ttmj views in which the full length of the styloid process was visible were considered, in total $87 \mathrm{tmj}$ 's were viewed. ORTHOPHOS XG3D X-ray system of SIRONA was used to obtain images. The field of vision is $8 \times 8 \mathrm{~cm}$ working at $85 \mathrm{KV}$ and $5 \mathrm{~mA}$, thepixel size is $0.1 \mathrm{~mm}$ and with the exposure time of 14.1 seconds. 3D reconstruction was also created. Patients with fracture or pathology in the region of the SP were not included in the study. None of the patients had symptoms of ossified SHC. The images were evaluated by a single specialist and all measurements were made by him. All measurements, length and angulations were 
made on the axial and transvers images and the morphology of the SP was identified using the $3 \mathrm{D}$-view.

The morphology of SHC was recorded to evaluate the general structural appearance and the number of segments and was categorized into 3 types as single segment ossification, two segment ossification and three segment ossification (Figures 1-3). The length was defined as the distance between the base of the SP and the tip of the ossified SHC. If there was segmental ossification of the SP, the distance was measured including the non-ossified parts (Figure 4). The antero posterior angle (APA) was defined as the angle made by the process with the perpendicular dropped from the lateral part of the external auditory meatus (Figure 5). The mediolateral angulation (MLA) was defined angle of intersection between the longitudinal axis of the SHC to the perpendicular dropped from the base of the process (Figure 6).

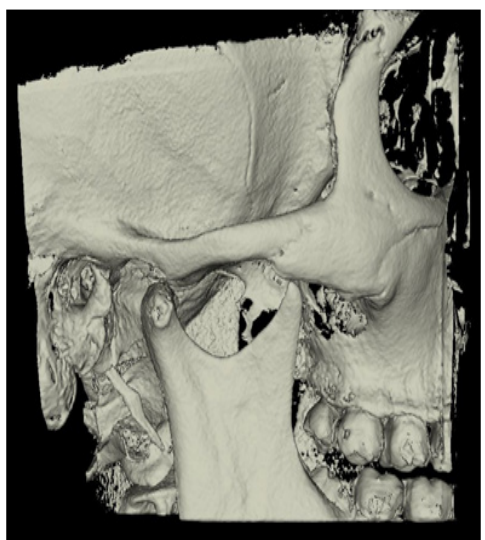

Figure I Shows single segment ossification.

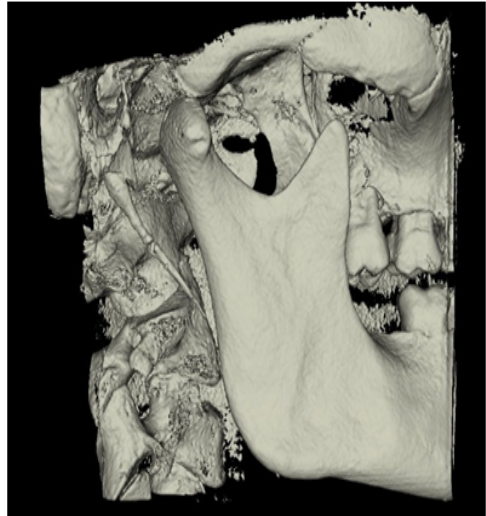

Figure 2 Shows two segment ossification.

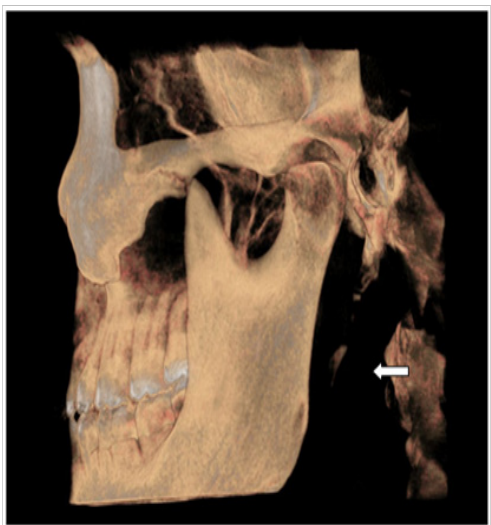

Figure 3 Shows three segment ossification.

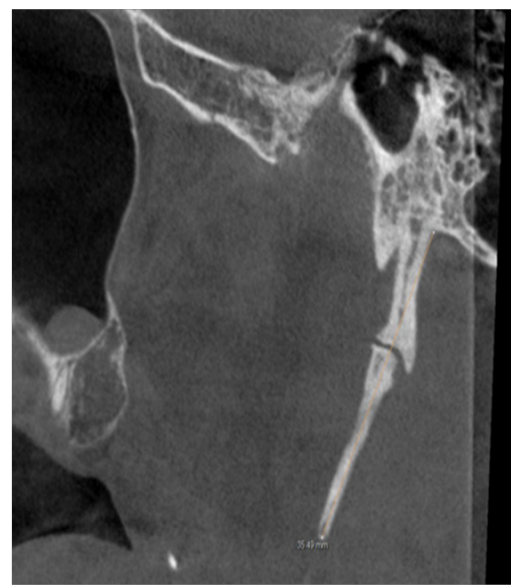

Figure 4 shows measurement of length from base to tip of SP.

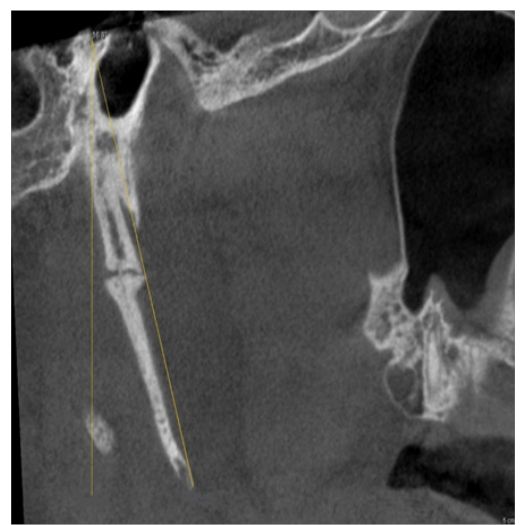

Figure 5 Shows measurement of Antero posterior angulation (APA).

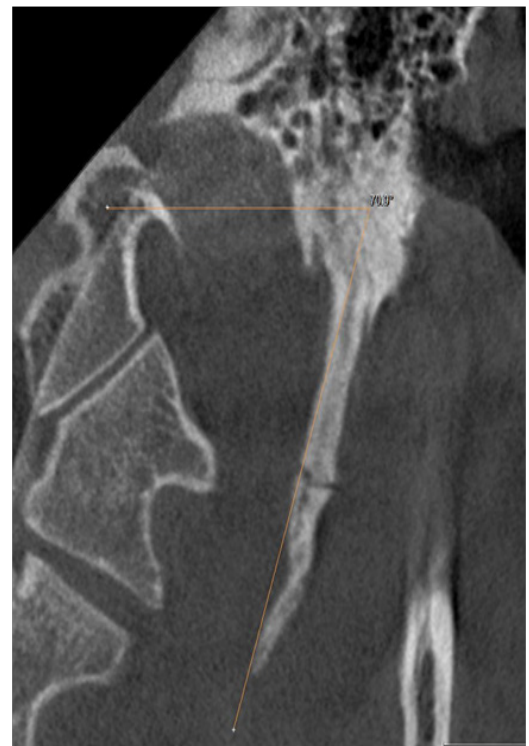

Figure 6 Shows Mediolateral angulation (MLA).

All data collected was recorded and tabulated in Microsoft Excel sheet and SPSS 20.0 for windows was used for statistical analysis. The length and angulations were recorded separately for the left and the right side. Pearson's correlation coefficient was used to test possible associations between the length of SP and angulations. A p-value $<0.05$ was considered to be statistically significant (Figure 7). 


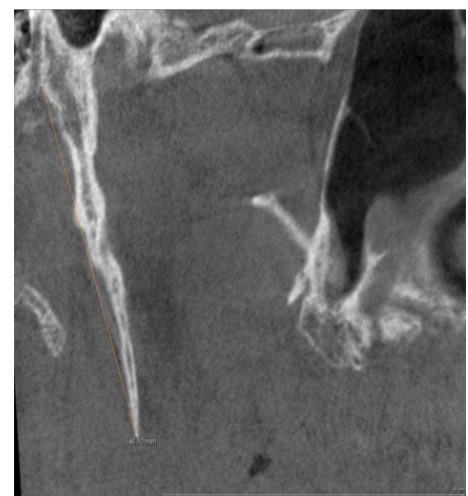

Figure 7 Shows elongated SP.

\section{Results}

Of the 87 scans of the 50patients, 26 were females and 24 were male patients (Table 1). The number of scans on the right side was 43 and that on the left side was 44 . The mean age group of patients in the study was 36.4 years with a minimum of 25 years and a maximum of 55years. The study showed that the mean length of SP in males was $32.10 \mathrm{~mm}$ with a range of $17.2 \mathrm{~mm}$ to $47.8 \mathrm{~mm}$ and in females it was $31.62 \mathrm{~mm}$ with a range of $18.5 \mathrm{~mm}$ to $45.3 \mathrm{~mm}$ with no statistical significance $(\mathrm{P}=0.332)$ (Table 2$)$. The mean length of $\mathrm{SP}$ on the right side was $32.35 \mathrm{~mm}$ and that on the left was $31.37 \mathrm{~mm}$, there was no significant difference between the sides (Table 3 ). It was also seen that there was no significant correlation between the length of SP and age $(\mathrm{P}=0.38)$.

Table I Gender and number of patients

\begin{tabular}{ll}
\hline Gender & Number \\
\hline Male & 26 \\
Female & 24 \\
Total & 50 \\
\hline
\end{tabular}

Table 2 Mean length in males and females

\begin{tabular}{ll}
\hline Gender & Mean length \\
\hline Male & $32.10 \mathrm{~mm}$ \\
female & $31.62 \mathrm{~mm}$ \\
\hline
\end{tabular}

Table 3 Mean length of SP on left and right side

\begin{tabular}{ll}
\hline Length & Mean \\
\hline Right & $32.35 \mathrm{~mm}$ \\
Left & $31.37 \mathrm{~mm}$ \\
\hline
\end{tabular}

The mean MLA in males was $80.6^{\circ}$ and in females it was $82.4^{0}$ were $\mathrm{P}$ was not significant $(\mathrm{P}=0.982)$ (Table 4). The MLA on the right side was $81.4^{\circ}$ and on the left it was $81.3^{\circ}$. There was no statistical significance between the right length of SP and MLA ( $\mathrm{P}=0.303)$ (Table 5), similarly no significance was noted between the left length of SP and MLA $(\mathrm{P}=0.15)$.

The mean APA was $25.2^{\circ}$ in males and $31.1^{\circ}$ in females (Table 6). The APA on the right side is $28.5^{\circ}$ and that on the left side was $28.3^{\circ}$ (Table 7) there was no statistical differences between the right length of SP and APA ( $p=0.30)$, the left length and APA also was notsignificant $(\mathrm{p}=0.23)$ in this study we found no correlation between length, age and agulation of the styloid process.

Table 4 Mean MLA in males and females

\begin{tabular}{ll}
\hline MLA & Mean \\
\hline Male & 80.6 \\
Female & 82.4 \\
\hline
\end{tabular}

Table 5 Mean MLA on right and left sides

\begin{tabular}{ll}
\hline MLA & Mean \\
\hline Right & $81.4^{0}$ \\
Left & $81.3^{\circ}$
\end{tabular}

Table 6 Mean APA in males and females

\begin{tabular}{ll}
\hline APA & Mean \\
\hline Male & $25.2^{\circ}$ \\
Female & $31.1^{\circ}$ \\
\hline
\end{tabular}

Table 7 Mean APA on right and left side

\begin{tabular}{ll}
\hline APA & Mean \\
\hline Right & $28.5^{\circ}$ \\
Left & $28.3^{\circ}$
\end{tabular}

Of the 87 images examined $30 \%$ showed elongated styloid $(>35 \mathrm{~mm})$ and there was no significant statistical difference between the length of the elongated SP and MLA and APA ( $p=0.29,0.24)$. Of the 3 types of morphological variation in the type of ossification of SP, on the right side $24 \mathrm{SHCs}(57.1 \%)$ showed single segment ossification, 15 SHCs (35.7\%) showed two segment ossification and 3SHCs (7.1\%) showed three segment ossification (Table 8). On the left side 23 SHCs (51.1\%) showed single segment ossification, 18SHCs (40\%) showed two segment ossification and 4SHCs $(8.8 \%)$ showed three segment ossifications (Table 9).

Table 8 Shows number of ossified segments on the right side

\begin{tabular}{ll}
\hline Number of ossified segments & Number \\
\hline Single & 24 \\
Double & 15 \\
Three & 3 \\
On the right side & \\
\hline
\end{tabular}

Table 9 Shows number of ossified segments on the left side

\begin{tabular}{ll}
\hline Number of ossified segments & Number \\
\hline Single & 23 \\
Double & 18 \\
Three & 4 \\
On the left side & \\
\hline
\end{tabular}

\section{Discussion}

CBCT is an imaging modality which gives $3 \mathrm{D}$ images at a lesser dose when compared to the conventional CT. Images can be viewed in the axial, sagittal and coronal planes with no overlapping of 
structures, so viewing and analyzing structures becomes more easy and reliable. Studies have suggested that $\mathrm{CBCT}$ provides accurate and reliable linear measurements for reconstruction and imaging of dental and maxillofacial structures. ${ }^{8,9}$

Several theories have been proposed for the etiopathogenesis of the Eagles syndrome which includes reactive hyperplasia, reactive metaplasia, anatomic variance, genetic hypothesis and degenerative process however the exact reason is not known, ${ }^{10}$ it has been proposed that increase in length and angulation may cause clinical symptoms.

Previous studies using conventional method reported values between $25-30 \mathrm{~mm}$ as normal ${ }^{11}$ however CBCT studies show normal lengths between $20-40 \mathrm{~mm}$, in a CBCT study by Illge et al., ${ }^{12}$ the mean length was $22.25 \mathrm{~mm},{ }^{12}$ in the present study where the mean length of SP on the righ side is $32.35 \mathrm{~mm}$ and on the left side it is $31.37 \mathrm{~mm}$ this is consistent with the study of Monsour et al. ${ }^{13}$ where length was $29.20 \pm 4.58 \mathrm{~mm}^{13}$ and Tushar et al., ${ }^{14}$ who reported a length of $23.2 \pm 10.70 \mathrm{~mm} .{ }^{14}$ So a length up to $30 \mathrm{~mm}$ can be accepted normal as there can be variation in the population. In the present study there was no significance in right and left side measurements which is in accordance with the study of Kosar et al. ${ }^{15}$ Gender predilection was not seen in the previous ${ }^{16-18}$ and the present study.

Elongated styloid process presents with symptoms that may include a dull aching pain localized in the throat, otalgia, hemifacial pain, dysphasia or an abnormal sensation of a foreign body in the pharynx..$^{2,5}$ It seems that the length is not enough to explain these complaints ${ }^{19}$ as many cases of elongated SP are asymptomatic, thus, other morphological characteristics of the SHC, such as the angle degree, are necessary to explain the causes. ${ }^{17,20}$ During assessment of the ossified SHC, angles are important parameters as SP is in close proximity to vital structures in the vicinity. Alterations in the APA or MLA of the ossified SHC may provoke these symptoms and they can be easily evaluated by $3 \mathrm{D}-\mathrm{CT} .{ }^{17}$

The mean APA angulation reported by Ilguy et al., ${ }^{12}$ in males is $23.8 \pm 5.12$ and in females it was 27.18 \pm 4.44 and Yavaz et al., ${ }^{18}$ also showed similar results. This is in accordance with the present study and no correlation was found between APA and SP's length which is in agreement with previous reported results. ${ }^{21}$ Changes in the APA may cause compression of the IX-XII ${ }^{\text {th }}$ cranial nerves, internal carotid artery and internal jugular vein ${ }^{22}$ which may cause some symptoms.

In a study by Ramadan et al it was seen that the MLA was 67$76^{17}$ and in a study by Basekin et al., ${ }^{23}$ it was $65-75^{23}$ which is in close proximity to the present study. Length and MLA also showed no correlation with the length of SHC. Decrease in angle may cause compression of internal carotid artery, while increased angles may cause a compression on the external carotid artery ${ }^{17}$ which is more likely to produce symptoms.

Ramadan et al. ${ }^{17}$ reported that the percentage of single segment ossification was $75.5 \%$; two or three-segment ossification was $24.5 \%$; complete ossification of the SHC was found in four SHCs. ${ }^{17}$ Where as in the present study on the right side single segment ossification was found in $57.1 \%$, two segments was found in $35.7 \%$ and three segments was detected in $7.1 \%$. On the left side; single segment ossification was $51.1 \%$, two segments were $40 \%$ and three segments was $8.8 \%$. in which we see a increase in the single segment ossification in both the studies.
Further studies are needed on a larger population as there is a lot of variation in values of length, angulations and there correlation to each other in previous studies. Further symptomatic patients should be considered to know the role of length and angulations in causing symptoms. Anatomical and morphological variations of the SP that is size, angulations, elongation, segmented, pseudo articulated, bent, partially ossified, absent can be best viewed on 3D CBCT, and they have to be considered when patent presents with symptoms.

\section{Conclusion}

This study indicates that with an increase in length there is no significant increase in angulations. Age and gender showed no correlation with length. Size, angulations and morphology can be assessed best on the 3D CBCT images. When patient presents with clinical symptoms during evaluation of the $\mathrm{SCH}$ complex length, angulations and morphology should be considered.

\section{Acknowledgements}

None.

\section{Conflict of interest}

Author declares that there is no conflict of interest.

\section{References}

1. Satyapal KS, Kalideen JM. Bilateral styloid chain ossification: case report. Surg Radiol Anat. 2000;22(3-4):211-212.

2. Balbuena L, Hayes D, Ramirez SG, et al. Eagle's syndrome (elongated styloid process). South Med J. 1997;90(3):331-334.

3. Kosar MI, Atalar MH, Sabanclogullari V, et al. Evaluation of the length and angulation of the styloid process in the patient with prediagnosis of Eagle syndrome. Folia Morphol. 2011;70(4):295-299.

4. Bagga MB, Kumar CA, Yeluri G. Clinicoradiologic evaluation of styloid process calcification. Imaging Sci Dent. 2012;42(3):155-161.

5. Hossein R, Kambiz M, Mohammad D, et al. Complete recovery after an intraoral approach for Eaglesyndrome. J Craniofac Surg. 2010;21(1):275-276.

6. Mazzetto MO, Kelly MA, Laís VM, et al. Anterior and Medial Angulations of the Styloid Process in Subjects with TMD: Clinical and Radiographic Findings. Brazilian Dental Journal. 2013;24(1):80-84.

7. Cohenca N, Simon JH, Roges R, et al. Clinical indications for digital imaging in dento-alveolar trauma. Part 1: traumatic injuries. Dent Traumatol. 2007;23(2):95-104.

8. Marmulla R, Wortche R, Muhling J, et al. Geometric accuracy of the New Tom 9000 Cone Beam CT. DentomaxillofacRadiol. 2005;34(1):28-31.

9. Lascala CA, Panella J, Marques MM. Analysis of the accuracy of linear measurements obtained by cone beam computed tomography (CBCT-New Tom). Dentomaxillofac Radiol. 2004;33(5):291-294.

10. Steinmann EP. Styloid syndrome in the absence of the elongated process. Acta Otolaryngol. 1968;66(4):347-356.

11. Palesy P, Murray GM, De Boever J, et al. The involvement of the styloid process in head and neck pain: a preliminary study. J Oral Rehabil. 2000;27(4):275-287.

12. Ilgüy D1, Ilgüy M, Fişekçioğlu E, et al. Assessment of the Stylohyoid Complex with Cone Beam Computed Tomography. Iran J Radiol. 2013;10(1):21-26. 
13. Monsour PA, Young WG. Variability of the styloid process and stylohyoid ligament in panoramic radiographs. Oral Surg Oral Med Oral Pathol. 1986;61(5):522-526.

14. Tushar P, Rajeshwari A, Balaji Rao B, et al. Incidence of elongated styloid process a radiographic study. JIOMR. 2011;23(3):S344-S346.

15. Kosar MI, Atalar MH, Sabanciogullari V. Evaluation of the length and angulation of the styloid process in the patient with pre-diagnosis of Eagle syndrome. Folia Morphol (Warsz). 2011;70(4):295-299.

16. Gozil R, Yener N, Calguner E, et al. Morphological characteristics of styloid process evaluated by computerized axial tomography. Ann Anat. 2001;183(6):527-535.

17. Ramadan SU, Gokharman D, Tuncbilek I. Assessment of the stylohoid chain by 3D-CT. Surg Radiol Anat. 2007;29(7):583-588.

18. Yavuz H, Caylakli F, Yildirim T, et al. Angulation of the styloid process in Eagle’s syndrome. Eur Arch Otorhinolaryngol. 2008;265(11):1393-1396.
19. Kim E, Hansen K, Frizzi J. Eagle syndrome: case report and review of the literature. Ear Nose Throat J. 2008;87(11):631-633.

20. Chuang WC, Short JH, McKinney AM, et al. Reversible left hemispheric ischemia secondary to carotid compression in Eagle syndrome: surgical and CT angiographic correlation. AJNR Am J Neuroradiol. 2007;28(1):143-145.

21. Andrei F, Motoc AGM, Didilescu AC, et al. 3D cone beam computed tomography study of the styloid process of the temporal bone. Folia Morphol. 2013;72(1):29-35.

22. Jung T, Tschernitschek H, Hippen $\mathrm{H}$, et al. Elongated styloid process: when is it really elongated? Dentomaxillofac Radiol. 2004;33(2):119-124.

23. Basekim CC, Mutlu H, Gungor A, et al. Evaluation of styloid process by three-dimensional computed tomography. Eur Radiol. 2005;15(1):134-139. 